\title{
Promoção da saúde nutricional em adolescente com doença falciforme: Estudo de
}

\section{caso único}

\author{
Promotion of nutritional health in adolescents with falciform disease: A single case study \\ Promoción de la salud nutricional en adolescentes con falciformas: Un único estudio de caso
}

Recebido: 11/05/2021 | Revisado: 18/05/2021 | Aceito: 31/05/2021 | Publicado: 14/06/2021

\author{
Amanda Maria Batista Meneghini \\ ORCID: https://orcid.org/0000-0001-5926-5589 \\ Universidade Federal de São João del-Rei, Brasil \\ E-mail: amandambm02@gmail.com \\ Luciana Netto \\ ORCID: https://orcid.org/0000-0001-6573-5006 \\ Universidade Federal de São João del-Rei, Brasil \\ luciananetto@ufsj.edu.br
}

\begin{abstract}
Resumo
O objetivo deste trabalho é descrever o perfil nutricional e clínico de um adolescente com doença falciforme, considerando o consumo de macro e micronutrientes, baseado nos hábitos alimentares e avaliação antropométrica. Trata-se de um estudo de caso único de um adolescente, sexo masculino, 16 anos de idade, diagnosticado com doença falciforme, sustentado no referencial teórico da dialética. A justificativa para o estudo se deu pela identificação da falha no acompanhamento nutricional de adolescentes com doença falciforme no Programa de Residência Multiprofissional em Saúde do Adolescente da Universidade Federal de São João del-Rei, Campus Centro-Oeste. A coleta de dados foi realizada no período de dezembro de 2020 a janeiro de 2021. Acredita-se que este estudo possa trazer benefícios de curto, médio e longo prazo para os adolescentes com doença falciforme, para suas famílias, para a comunidade, para as instituições formadoras e para a ciência, uma vez que a identificação do estado nutricional dos adolescentes com a doença falciforme, favorece o planejamento de ações voltadas para a promoção da saúde, de modo a minimizar o prejuízo para a qualidade de vida em todo o ciclo de vida do adolescente.
\end{abstract}

Palavras-chave: Adolescente; Doença falciforme; Estado nutricional; Promoção da saúde.

\begin{abstract}
The objective of this work is to describe the nutritional and clinical profile of an adolescent with sickle cell disease, considering the consumption of macro and micronutrients, based on eating habits and anthropometric assessment. This is a single case study of a 16-year-old male teenager diagnosed with sickle cell disease, based on the theoretical framework of dialectics. The justification for the study was given by the identification of the failure in the nutritional monitoring of adolescents with sickle cell disease in the Multiprofessional Residency Program in Adolescent Health at the Federal University of São João del-Rei, Campus Centro-Oeste. Data collection was carried out from December 2020 to January 2021. It is believed that this study may bring short, medium and long term benefits for adolescents with sickle cell disease, for their families, for the community, for the educational institutions and science, since the identification of the nutritional status of adolescents with sickle cell disease favors the planning of actions aimed at promoting health, in order to minimize the damage to the quality of life in the entire health cycle. teenager's life.
\end{abstract}

Keywords: Adolescent; Health promotion; Nutritional status; Sickle cell disease.

\begin{abstract}
Resumen
El objetivo de este trabajo es describir el perfil nutricional y clínico de un adolescente con anemia falciforme, considerando el consumo de macro y micronutrientes, con base en los hábitos alimentarios y la evaluación antropométrica. Se trata de un estudio de caso único de un adolescente de 16 años diagnosticado con anemia falciforme, basado en el marco teórico de la dialéctica. La justificación del estudio fue dada por la identificación de la falla en el seguimiento nutricional de los adolescentes con anemia falciforme en el Programa de Residencia Multiprofesional en Salud del Adolescente de la Universidad Federal de São João del-Rei, Campus Centro-Oeste. La recolección de datos se realizó desde diciembre de 2020 hasta enero de 2021. Se cree que este estudio puede traer beneficios a corto, mediano y largo plazo para los adolescentes con anemia falciforme, para sus familias, para la comunidad, para las instituciones educativas y para la ciencia. ya que la identificación del estado nutricional de los adolescentes con anemia falciforme, favorece la planificación de acciones orientadas a la promoción de la salud, con el fin de minimizar el daño a la calidad de vida en todo el ciclo de salud del adolescente.
\end{abstract}

Palabras clave: Adolescente; Enfermedad de célula falciforme; Estados nutricionales; Promoción de la salud. 


\section{Introdução}

A doença falciforme (DF) é uma condição genética autossômica recessiva, causada pela presença de uma anomalia na hemoglobina. É uma das hemoglobinopatias mais frequentes na população e um problema de saúde pública reconhecida em todo o mundo. A hemoglobina tem a função do transporte de oxigênio para todo o corpo. A hemoglobina A (HbA) é o pigmento encontrado nos eritrócitos e, em combinação com o elemento ferro, é responsável por carrear o oxigênio dos pulmões para todo o organismo, entretanto, na pessoa com DF, ocorre a mutação de um gene da HbA onde as hemácias têm sua forma alterada. Essa alteração leva à produção da hemoglobina $\mathrm{S}(\mathrm{HbS})$, que na desoxigenação, resulta em falcização de glóbulos vermelhos, tornando-os parecidos com uma foice (Dahmani et al., 2016; Wasnik \& Akarte, 2017).

A DF é um distúrbio genético que leva os portadores a apresentarem sinais e sintomas de anemia crônica, como palidez cutaneomucosa, fadiga e tolerância reduzida aos esforços. Por se tratar de uma anemia hemolítica, um sinal comum entre os pacientes é a icterícia. Outras complicações que podem ocorrer: hipertensão arterial pulmonar com a consequente insuficiência cardíaca; hematúria e dificuldade em concentrar a urina. Também são comuns as úlceras cutâneas refratárias de perna, que levam meses e, às vezes, anos para cicatrizar (Cehmob, 2018; Brasil, 2018).

O termo anemia não indica um diagnóstico, mas sim um sinal de doença, que é empregado quando ocorre diminuição dos eritrócitos ou da hemoglobina circulante. A anemia falciforme (AF) é a forma mais grave da DF e se deve à transmissão do gene alterado de ambos os pais para a criança, que se torna homozigota, com dupla hemoglobina S (HbSS) (Zago \& Pinto, 2007). Existem outras hemoglobinopatias que, quando combinadas com HbS, formam o grupo das DF: hemoglobina $\mathrm{C}$ (HbC), hemoglobina $\mathrm{D}(\mathrm{HbD})$, hemoglobina $\mathrm{E}(\mathrm{HbE})$ e beta-talassemias.

Cerca de 5\% da população mundial carrega um gene responsável por anomalia de hemoglobina, sendo que esta prevalência pode chegar a 25\% em determinadas regiões (Dahmani et al., 2016; Li-thiao-te et al., 2018). Pelo fato de a doença ser de caráter ancestral e étnico, alguns indicadores de nascimento, mortalidade e morbidez demonstram maior prevalência, geralmente na população de negros, pardos e afrodescendentes (Santos et al., 2019). No Brasil, é relatada a maior incidência de nascidos vivos diagnosticados com doença falciforme nos estados da Bahia, Rio de Janeiro, Minas Gerais, Maranhão, Goiás, Pernambuco, Espírito Santo, Rio Grande do Sul, Paraná e Santa Catarina, respectivamente (Brasil, 2014). Destaca-se a importância de atentarmos para a herança de desigualdade social que envolve esse grupo de pessoas.

Além das manifestações crônicas, alguns episódios agudos podem ocorrer, como as crises vaso-oclusivas recorrentes, hemolíticas, de sequestro esplênico e dolorosas, com o tempo, podem ocorrer danos aos órgãos. Portadores de DF apresentam uma ativação defeituosa da via alternativa do complemento, levando a um risco aumentado de infecção pela função imunológica comprometida (Mandese et al., 2016; Wasnik \& Akarte, 2017; Li-thiao-te et al., 2018). Um quadro clínico grave da DF é marcado pela alta frequência de transfusão precoce, complicações infecciosas graves, condição inflamatória constante, caracterizada por elevação das proteínas inflamatórias e estado nutricional comprometido (Dahmani et al., 2016).

$\mathrm{O}$ aumento da taxa de eritropoiese e do trabalho cardíaco, devido à anemia crônica, aumenta a demanda metabólica e as necessidades de proteína, energia e minerais na alimentação. Mesmo nos períodos sem crises ou complicações, a hemólise crônica continua, bem como, a vaso-oclusão que resultam no aumento do metabolismo proteico e balanço nitrogenado negativo. Todos esses fatores agem sobre a taxa metabólica basal do indivíduo com DF, fazendo com que seja $20 \%$ maior que na população normal. Ou seja, mesmo com a ingestão alimentar adequada, se comparada com controles normais, o portador da DF é considerado relativamente subnutrido (Anvisa, 2001).

Atualmente, a população de adolescentes e jovens de 10 a 24 anos de idade no Brasil, pelo censo de 2010, compreende um total de 51.402.821 pessoas, o que equivale a $27 \%$ da população. A adolescência é caracterizada pelo período de 10 a 19 anos, de acordo com o Ministério da Saúde e prescrita pela Organização Mundial da Saúde (OMS) (Brasil, 2018). É 
um período de crescimento intenso, fase em que se adquire $20 \%$ do peso e $50 \%$ da estatura final do adulto. A massa óssea aumenta em 45\%, vários tecidos e órgãos aumentam, bem como a massa eritrocitária. A deficiência de macro e micronutrientes na adolescência pode retardar o crescimento, a maturação sexual e favorecer o surgimento das anemias carenciais, sendo a deficiência de ferro a mais comum, seguida pela deficiência de ácido fólico e de vitamina B12. Já nos indivíduos com DF é necessária a reposição de ácido fólico pela sua redução significativa devido à hemólise crônica. Também, é necessário acompanhar rigorosamente as concentrações de ferro no organismo que pode acarretar o acúmulo desse mineral, sobrecarregando o sangue, devido à hemólise e, mas também após as hemotransfusões que poderão ocorrer (Mandese et al., 2016; Brasil, 2018).

A desnutrição é um componente prejudicial para qualquer indivíduo, e em crianças e adolescentes com DF podem interferir mais ainda no prognóstico da doença, uma vez que esse grupo já possui necessidades nutricionais aumentadas para compensar o crescimento e desenvolvimento corporal, retratando assim um importante impacto na qualidade de vida e saúde. Além da desnutrição acelerar os processos infecciosos e de morbimortalidade na doença (Souza et al., 2011). Dentre os indivíduos com DF grave, os adolescentes são os que exigem uma maior atenção clínica e nutricional, pois apresentam hospitalizações constantes e crises dolorosas, fatores esses que podem oportunizar uma redução na ingestão de alimento, e consequentemente, limitar o fornecimento de micronutrientes essenciais para o desenvolvimento esperado na adolescência (Santos et al., 2019).

Nas duas últimas décadas, é observada constante melhora das taxas de sobrevivência, manejo, e em relação as internações, readmissões e complicações agudas das pessoas com DF. No entanto, a sobrevivência é menor no período final da adolescência e nos adultos jovens (Cehmob, 2018). Uma possível explicação são as lacunas no atendimento durante esse momento de transição da infância para a adolescência. Soma-se a isso a insegurança por parte dos pais, que não sabem se mantém os filhos em acompanhamento de saúde com o profissional pediatra ou clínico geral, julgando, por vezes, ser necessário somente o acompanhamento do desenvolvimento da doença com o hematologista. No adolescente com DF, de forma geral em doenças crônicas, é difícil contar com a adesão do paciente ao regime terapêutico, pois, para trabalhar com adolescente é necessário considerar a complexidade e as limitações presentes nessa etapa da vida (Moreira et al., 2017).

Elemento fundamental para garantir qualidade de vida ao ser humano é o autocuidado, que consiste em ações feitas pelo próprio indivíduo para manutenção da saúde e bem-estar, como cuidados cotidianos de higiene, alimentação e medicação. Um problema encontrado no indivíduo com DF, é o fato de se limitarem ao acompanhamento nos hemocentros, permanecendo na tenção secundária e não retornam à atenção primária, o que fragmenta o acompanhamento de saúde na sua integralidade. No caso da pessoa com DF, conhecer a enfermidade e realizar o autocuidado torna-se ainda mais importante. Além do acompanhamento de saúde disposto na atenção primária, o Centro de Educação e Apoio para Hemoglobinopatias (CehmobMG), parceiro do Núcleo de Ações e Pesquisa em Apoio Diagnóstico (Nupad) da Faculdade de Medicina da UFMG e Fundação Hemominas são as referências para acompanhamento desses indivíduos.

$\mathrm{O}$ adolescente passa por várias transformações nessa etapa da vida, sendo de suma importância manter os cuidados com a sua saúde. Os riscos das deficiências nutricionais é um problema importante entre adolescentes com DF, em função das implicações sobre sua condição clínica e o impacto negativo das complicações sobre seu desenvolvimento. Frente a isso, o objetivo desse estudo é descrever o perfil nutricional e clínico de um adolescente com DF, considerando o consumo de macro e micronutrientes, baseado nos hábitos alimentares e avaliação antropométrica. 


\section{Métodos}

Trata-se de um estudo de caso único de um adolescente, sexo masculino, 16 anos de idade, diagnosticado com doença falciforme, sustentado no referencial teórico da dialética (Santos, Santos, Mascarenhas \& Melo, 2018). O estudo de caso como método de pesquisa científica atende, de forma mais adequada à proposta envolvendo situações que merecem uma atenção maior e mais aprofundada, em que o pesquisador tem que imergir na pesquisa para entender como funciona o objeto investigado. E que, segundo Gil (2002), é uma tarefa praticamente impossível mediante outras metodologias, sendo esta uma modalidade de pesquisa utilizada nas ciências sociais e biomédicas, constituídos tanto de um único, quanto de múltiplos casos.

A justificativa para o estudo se deu pela identificação da falha no acompanhamento nutricional de adolescentes com DF no Programa de Residência Multiprofissional em Saúde do Adolescente (REMSA) da Universidade Federal de São João del-Rei (UFSJ), Campus Centro-Oeste. Para acesso ao adolescente e seu responsável, firmou-se uma parceria com o projeto "Educar Falciforme", nome genérico dado ao projeto de extensão e pesquisa denominado "Intervenções Educativas com um grupo de Famílias de Crianças e Adolescentes com Doença Falciforme em um Município do Centro Oeste Mineiro" também da UFSJ.

A coleta de dados foi realizada exclusivamente pela pesquisadora e aconteceu no período de dezembro de 2020 a janeiro de 2021. Considerando a recomendação dos órgãos sanitários de manutenção do afastamento social decorrente da pandemia pela COVID-19, todos os contatos ocorreram de forma remota, com uso de tecnologias da informação e comunicação (TICs), como: chamadas telefônicas, WhatsApp (aplicativo multiplataforma de mensagens instantâneas e chamadas de texto, imagem, áudio e vídeo) e Google Forms (aplicativo de gerenciamento de pesquisas lançado pelo Google).

Para obter informações referentes aos hábitos alimentares e estilo de vida foram utilizados dois questionários adaptados: a Ficha de Anamnese Nutricional, e o Inquérito de Consumo Alimentar, do tipo Recordatório 24 horas (R24h), com o objetivo de analisar o estado nutricional do adolescente a partir da ingesta alimentar e histórico clínico. Foi necessária a adaptação dos instrumentos de coleta para atender à especificidade do público-alvo do estudo. De forma a auxiliar, o adolescente, no preenchimento do R24h, foi orientado a recordar o tamanho da porção dos alimentos ingeridos, padronizando e aumentando a confiabilidade das informações relatadas. Para tanto, foi fornecido um modelo fotográfico de medidas caseiras (copo, caneca, prato e talheres), nas dimensões pequena, média e grande. Para aprofundar, compreender e explanar o conteúdo deste estudo, os inquéritos foram aplicados também ao responsável pelo adolescente, para confirmação das informações, que ocorreram separadamente, respeitando a individualidade de ambos.

Todas as informações foram digitadas com registro direto em notebook. A transcrição da entrevista foi feita imediatamente após sua realização, para garantir sua qualidade. Os alimentos referidos no R24h em medidas caseiras foram convertidos em gramas utilizando o software Dietbox ${ }^{\circledR}$ para a entrada de dados de consumo alimentar, tornando o mais fidedigno possível o cálculo estimado de energia e nutrientes (Dietbox, 2021). De forma a elucidar uma apreciação crítica dos dados apresentados nos questionários com a percepção do adolescente frente às suas escolhas alimentares, foi realizada entrevista semiestruturada com o adolescente e seu responsável.

Para classificação antropométrica, foram utilizados os dados referentes ao peso e estatura, informados no momento da aplicação da anamnese nutricional. Os dados utilizados são recentes, visto que são aferidos mensalmente em consulta médica no hemocentro de referência. Foram empregados para cálculo do indicador Índice de Massa Corporal por Idade (IMC/I) e Estatura por Idade (E/I), onde o sexo também é determinante nesse parâmetro. O índice de Massa Corporal (IMC) foi obtido a partir da divisão do peso corporal em quilogramas $(\mathrm{kg})$, pela altura em metro $(\mathrm{m})$, elevada ao quadrado $\left(\mathrm{IMC}=\right.$ peso/altura $\left.{ }^{2}\right)$ seguindo a classificação e os pontos de corte para adolescentes e o escore-Z que é um estimador do estado nutricional que 
quantifica a distância de um valor observado em relação à mediana de uma população propostos pela organização Mundial da Saúde (Who, 2007).

O cálculo da necessidade energética de consumo diário do adolescente baseou-se no requerimento estimado de energia (EER), que foi calculado pelo gasto energético, nível de exercícios e pelas necessidades para o crescimento e desenvolvimento em pessoas saudáveis (Iom, 2002).

Após a coleta, os dados foram digitados em planilha do Microsoft Excel 2010. Foi realizada a análise descritiva dos dados obtidos quantitativos. A análise dos dados da entrevista foi feita a partir de recursos da análise de conteúdo, na perspectiva de Bardin (2011). O adolescente e seu responsável cientes que as pesquisadoras serão as únicas a terem acesso aos dados coletados, e tomarão as providências para garantia do sigilo e anonimato, concordaram em participar do estudo após assinatura do Termo de Assentimento Livre e Esclarecido (TALE) e seu responsável assinar o Termo de Consentimento Livre e Esclarecido (TCLE).

O projeto de pesquisa que deu origem a esse estudo foi aprovado no Comitê de Ética em Pesquisa da UFSJ, Parecer $\mathrm{n}^{\circ}$ 4.319.748, Certificado de Apresentação para Apreciação Ética nº 34178820.6.0000.5545.

\section{Resultados e Discussão}

A aplicação da Ficha de Anamnese Nutricional revela que o adolescente não pratica nenhuma atividade física, pois sente muita fadiga com a realização de qualquer esforço físico e apresenta arritmia cardíaca, causalidades da doença e da medicação, como informado pelo responsável, cujo esclarecimento veio da orientação do médico que faz o acompanhamento do adolescente no hemocentro. Sobre o consumo hídrico, o adolescente relata que é baixo, pois não lembra de hidratar-se "[...] consumo em torno de 500ml de água pura, e cerca de 1000ml diluído em suco de pozinho", industrializado."

Salienta-se que tais atividades são habituais na faixa etária da adolescência, por estarem intimamente ligadas às atividades educacionais nas escolas, podendo se beneficiar com o exercício e o desenvolvimento psicossocial e pessoal envolvido na realização da educação física e em situações de lazer. Somado a isso, estas atividades são fundamentais por favorecem o desenvolvimento das capacidades físicas, cognitivas, afetivas, de integração e inserção social. Devendo assim o adolescente ser encorajado a realizar estas atividades, e faz-se necessário que estas sejam regulares, moderadas e o esforço progrida lentamente, sendo o monitoramento do esforço físico realizado pelo próprio adolescente, dado que exercícios que exijam muito esforço físico podem desencadear crises de dor, e a ingestão de água deve ser constante (Marques, 2015).

Os dados empíricos destacam que o adolescente não havia realizado acompanhamento nutricional antes de ser encaminhado pelo projeto Educar Falciforme ao Programa da REMSA, e também, nunca seguiu uma dieta específica. Alega bom apetite, porém, com frequentes enjoos pela manhã, o que interfere nas refeições neste período, pois não consegue se alimentar por medo de induzir vômitos. Com isso, episódios de refluxo gastroesofágico e presença de pirose são constantes. Sobre alterações gastrointestinais, o adolescente refere obstipação, e diz que "[...] o funcionamento do intestino é um pouco lento, às vezes fico até quatro dias seguidos sem ir ao banheiro". Esses sintomas podem ser efeitos colaterais devido a medicação Hidroxiureia.

O adolescente informa, ainda, que havia uma boa higiene do sono, porém, desde as mudanças dos hábitos dele e da família causados pelo período pandêmico, tem tido insônia, hábitos noturnos, e com isso, alterando todo o ciclo de suas atividades no dia seguinte. Uma vez que a higiene do sono é de suma importância na liberação de hormônios, como o Growth Hormone $(\mathrm{GH})$ conhecido como hormônio do crescimento, alterações na sua produção pela mudança no padrão de sono e repouso somado à DF pode causar maior prejuízo no desenvolvimento estatural do adolescente (Sbp, 2021). 
Sobre os episódios de internação, o adolescente lembra que ainda era criança quando as internações ocorreram, mas não sabe dizer ao certo quantas foram. Em relato sobre o histórico de internações do adolescente o responsável diz que "[...] as transfusões sanguíneas começaram na infância. Foram muitas, a ponto de não lembrar quantas foram ao certo. A primeira ocorreu no primeiro ano de vida. Quando criança ele tinha episódios de pneumonia, foram várias vezes, e nesses episódios sempre internava e tomava transfusão sanguínea. Isso ocorreu até por volta dos 8 anos. Depois disso não internou mais”.

Em relação ao consumo de suplementação de vitaminas e minerais, bem como a medicação utilizada, o responsável relata que segue a orientação médica de suplementação diária de ácido fólico (vitamina B9), e uso da hidroxiuréia 500mg, intercalada (2 cápsulas em um dia, no dia seguinte 3 cápsulas). Segundo o responsável, o médico orientou que poderia ocorrer náusea e queda de cabelo devido ao uso da medicação, fato que tem ocorrido. O responsável diz que "[...] devido à melhora significativa do estado de saúde dele, desde que iniciou a hidroxiuréia, esses efeitos são aceitáveis". Contudo, o adolescente não tem conhecimento de que esses efeitos colaterais apresentados são devidos à medicação. Nesse ponto, considerando a influência dos aspectos estéticos na adolescência, o responsável diz "[...] tenho medo dele saber e não querer tomar mais".

Quanto aos exames bioquímicos, o responsável informa que o adolescente realiza mensalmente no hemocentro os exames de referência (hemograma completo e dosagem de ferro sério) para controle da DF, e que todos os resultados estão dentro dos parâmetros adequados, apresentando quadro clínico estável. Porém, os exames complementares para acompanhamento do desenvolvimento do adolescente como a dosagem de colesterol, triglicérides, glicose, vitaminas e minerais, já tem um tempo que não são realizados.

Os dados antropométricos utilizados foram os relatados pelo adolescente e confirmados com seu responsável, a saber: peso 58,0 kg e estatura de $1,72 \mathrm{~m}$. O adolescente relatou que devido à mudança de hábitos por causa da pandemia da COVID19 , o seu peso oscilou nesse período. O IMC do adolescente correspondeu a $19,6 \mathrm{~kg} / \mathrm{m}^{2}$, apresentando classificação $\geq$ Escore-z -2 e $\leq$ Escore- $\mathrm{z}+1$ em eutrofia, ou seja, adequado para a idade. A estatura do adolescente apresentou $\geq$ Escore- $\mathrm{z}-2$, e também se encontra adequada para a idade.

Quando comparado à estatura, o consenso literário aponta que o peso de crianças e adolescentes com dá DF é abaixo do normal, fator esse apresentado por Cox et al. (2011), sendo um dos estudos mais atuais abrangendo uma maior análise amostral totalizando 1041 indivíduos com DF, e idade entre 5 - 48 anos, com prevalência de maior déficit de estatura durante a adolescência. Mandese e colaboradores (2019) relatam que entre os indivíduos de sua amostra, cerca de 50\% dos pacientes eram púberes. Trata-se de uma diferença marcante na adolescência já que o estirão de crescimento ocorre aproximadamente dois anos e meio mais tarde no adolescente com DF. O desenvolvimento esquelético atrasa-se em relação à cronológica como consequência do efeito cumulativo dos infartos ósseos, do baixo peso e da disfunção hormonal secundária à doença (Anvisa, 2002).

Para o cálculo da necessidade energética de consumo diário do adolescente foi utilizada a fórmula para estimativa da necessidade energética (EER) para meninos eutróficos de 9 a 18 anos de idade, considerando o nível de atividade física (NAF) realizado: $\mathrm{EER}=88,5-(61,9 \mathrm{x}$ idade[anos] $)+\mathrm{NAF} \times(26,7 \mathrm{x}$ peso[kg] $+903 \mathrm{x}$ altura[metros] $)+25$ (kcal para crescimento), que resultou no valor de necessidade energética diária para o adolescente de 2.207,46 kcal/dia, sem considerar o aumento das demandas nutricionais intrínsecas à DF.

Os dados do Recordatório 24h proveu informações sobre ingestão alimentar do adolescente pelo período de 6 (seis) dias, sendo o adolescente orientado a registrar o alimento na hora do consumo, para não se basear na memória do que foi consumido. Foram coletados os dados no que se refere ao consumo calórico, de macronutrientes que são os carboidratos, lipídeos e proteínas, e dos micronutrientes vitaminas e minerais. Incluindo no registro o consumo de bebidas (líquidos).

Os macronutrientes são nutrientes necessários ao organismo em maiores quantidades e que conferem os valores de energia que os alimentos fornecem. Cada macronutriente exerce sua função específica no organismo e o equilíbrio alimentar 
do ser humano depende da proporção ideal entre eles. Os micronutrientes selecionados para estimar a quantificação foram os mais citados na literatura relacionados no prognóstico da DF, principalmente na renovação celular sanguínea, e, concomitantemente, essenciais também para o desenvolvimento sadio da adolescência, sendo estes: vitaminas (A, B9, B12, C e D) e minerais (Cálcio, Ferro, Magnésio, Potássio, Sódio e Zinco).

A análise dos dados empíricos corrobora os achados na literatura. Para esse estudo, procedeu-se à divisão dos dados quantitativos em três categorias. I- Consumo calórico e de macronutrientes (Tabela 1). II- Consumo de micronutrientes representado pelas Vitaminas (Tabela 2). III- Consumo de micronutrientes representados pelos Minerais (Tabela 3).

Tabela 1 - Percentual do consumo Calórico e dos Macronutrientes: Carboidratos, Lipídeos e Proteínas, de acordo com a alimentação fornecida ao adolescente pelo período de 6 dias, segundo dados do Recordatório Alimentar 24h.

\begin{tabular}{|c|c|c|c|c|c|c|c|c|}
\hline \multirow[t]{2}{*}{ Nutrientes } & \multirow{2}{*}{$\begin{array}{c}\text { Necessidades e } \\
\text { Recomendações } \\
\text { Nutricionais* }\end{array}$} & \multicolumn{7}{|c|}{ Valores Recordatório Alimentar 24h } \\
\hline & & $\begin{array}{l}\text { Segunda- } \\
\text { feira }\end{array}$ & $\begin{array}{c}\text { Terça- } \\
\text { feira }\end{array}$ & $\begin{array}{l}\text { Quarta- } \\
\text { feira }\end{array}$ & $\begin{array}{c}\text { Quinta- } \\
\text { feira }\end{array}$ & $\begin{array}{c}\text { Sexta- } \\
\text { feira }\end{array}$ & Sábado & $\begin{array}{c}\text { Média } \\
\text { percentual }\end{array}$ \\
\hline Calorias & $2.207,46$ & $2.568,42$ & $1.576,28$ & $1.944,73$ & $1.680,03$ & $1.115,39$ & $1.351,46$ & $1.706,05$ \\
\hline $\mathrm{Kcal} / \mathrm{dia}$ & & $(116,3 \%)$ & $(71,4 \%)$ & $(88,0 \%)$ & $(76,1 \%)$ & $(50,5 \%)$ & $(61,2 \%)$ & $(77,2 \%)$ \\
\hline Carboidratos & $45-65 \%$ & $49,2 \%$ & $69,9 \%$ & $53,6 \%$ & $40,7 \%$ & $69,5 \%$ & $59,0 \%$ & $56,9 \%$ \\
\hline Lipídeos & $25-35 \%$ & $26,6 \%$ & $20,4 \%$ & $31,6 \%$ & $35,2 \%$ & $16,0 \%$ & $24,1 \%$ & $25,6 \%$ \\
\hline Proteínas & $10-30 \%$ & $24,2 \%$ & $9,6 \%$ & $14,8 \%$ & $24,1 \%$ & $14,5 \%$ & $16,8 \%$ & $17,3 \%$ \\
\hline
\end{tabular}

*Recomendações de macronutrientes baseadas na Ingestão Diária Recomendada de acordo com o sexo e a idade (IOM, 2010); e recomendação Calórica baseada na Estimativa da Necessidade Energética (EER/2002).

Fonte: Autores.

Verifica-se, na Tabela 1, que somente em um dia, o adolescente ultrapassou o aporte energético estimado de 2.207,46 kcal/dia, apresentando uma média de ingesta diária semanal de 1.706,05 kcal. No campo de observações do R24h o adolescente citou que nos dias em que a ingesta alimentar e calórica foi baixa, houve a presença de enjoos pela manhã, o que levou ao não consumo de alimentos neste período. A inadequação da ingestão total de calorias e macronutrientes apresentados nesse estudo também foi observada em Mandese et al. (2016).

Os limites estabelecidos pelo Institute of Medicine (IOM), recomenda, para a faixa etária de 4 a 18 anos, que a contribuição dos macronutrientes deva variar de $45 \%$ a $65 \%$ para carboidratos, $10 \%$ a $30 \%$ para proteínas e de $25 \%$ a $35 \%$ para lipídios. Esses limites percentuais foram classificados para a população dos Estados Unidos e Canadá, e estão associados ao atendimento das necessidades nutricionais e à diminuição no risco de doenças crônicas não transmissíveis. Por outro lado, o Guia Alimentar para a População Brasileira (GAPB) estipula a distribuição de $55 \%$ a $75 \%$ para carboidratos, $15 \%$ a $30 \%$ para lipídios e de $10 \%$ a 15\% para proteínas (Veiga et al., 2013).

No estudo de Veiga et al. (2013), a amostra de adolescentes considerando a distribuição percentual no consumo energético total de macronutrientes apresentou-se para lipídios (27\%), carboidratos (57\%) e para proteínas (16\%). As médias percentuais do consumo energético total de macronutrientes observadas neste estudo de caso único foram similares a de Veiga (2013), estando os lipídios (25,6\%), carboidratos (56,9\%) e proteínas (17,3\%), dentro dos padrões recomendados para IOM, e para o GAPB as proteínas se encontram ligeiramente acima do preconizado. Além da inadequação da distribuição energética da média percentual de macronutrientes, como o adolescente do caso possui DF, uma doença crônica que aumenta em cerca de 20\% suas demandas energéticas (Anvisa, 2002), o mesmo acabou não atingindo as necessidades recomendadas. Apesar disso, o IMC do adolescente ainda apresenta estado de eutrofia. Uma explicação para isso poderia ser a compensação de maior 
consumo energético em dias atípicos, o baixo gasto energético com atividade física, ou até mesmo o registro incompleto do R24h.

A inconstante distribuição dos macronutrientes pode influenciar, além da oferta energética, nos substratos de componentes estruturais, imunológicos e metabólicos. Em todas as fases da vida, e na adolescência não é diferente, o consumo alimentar deve ser o mais variado possível, devendo conter alimentos de todos os grupos (Veiga et al., 2013). A faixa recomendada de ingestão energética reflete as diferentes necessidades dos adolescentes. Alguns levantamentos como de Cox et al. 2011; Mandese et al. 2019, revelaram que, entre todos os grupos etários, os adolescentes tinham a maior prevalência de estado nutricional insatisfatório. Além disso, é de suma importância no indivíduo com DF atentar-se para o estado nutricional total, pois ele a desnutrição proteica está associada à dificuldade na cicatrização pela redução da produção de fibroblastos, síntese de colágeno e menor capacidade de reparação tecidual. Fator importante este devido à tendência do acometimento de úlceras de membro inferiores nos indivíduos com DF, principalmente na fase da adolescência (Veiga et al., 2013).

Tabela 2 - Percentual do consumo dos micronutrientes: Vitaminas, de acordo com a alimentação fornecida ao adolescente pelo período de 6 dias, segundo dados do Recordatório Alimentar 24h.

\begin{tabular}{lcccccccc}
\hline Nutrientes & $\begin{array}{c}\text { Necessidades e } \\
\text { Recomendações }\end{array}$ & \multicolumn{7}{c}{ Valores Recordatório Alimentar 24h } \\
\cline { 3 - 8 } & Nutricionais* & Segunda- & Terça- & Quarta- & Quinta- & Sexta- & Sábado & Média \\
feira & feira & feira & feira & & & percentual \\
\hline Cálcio & $1.300,00 \mathrm{mg}$ & 761,04 & 387,96 & 171,39 & 394,39 & 361,75 & 175,80 & $36,01 \%$ \\
& & $(58,5 \%)$ & $(29,8 \%)$ & $(13,1 \%)$ & $(30,3 \%)$ & $(27,8 \%)$ & $(13,5 \%)$ & \\
\multirow{2}{*}{ Ferro } & \multirow{2}{*}{$11,00 \mathrm{mg}$} & 25,31 & 10,40 & 13,82 & 15,91 & 12,30 & 12,91 & $136,8 \%$ \\
& & $(230,0 \%)$ & $(91,5 \%)$ & $(125,6 \%)$ & $(144,6 \%)$ & $(111,8 \%)$ & $(117,3 \%)$ & \\
\multirow{2}{*}{ Magnésio } & \multirow{2}{*}{$410,00 \mathrm{mg}$} & 399,01 & 228,70 & 267,65 & 228,89 & 300,66 & 252,41 & $68,13 \%$ \\
& & $(97,3 \%)$ & $(55,7 \%)$ & $(65,2 \%)$ & $(55,8 \%)$ & $(73,3 \%)$ & $(61,5 \%)$ & \\
Potássio & \multirow{2}{*}{$4.700,00 \mathrm{mg}$} & $3.584,71$ & $1.840,73$ & $2.330,06$ & $1.927,22$ & $2.160,09$ & $1.905,70$ & $48,7 \%$ \\
& & $(76,2 \%)$ & $(39,1 \%)$ & $(49,5 \%)$ & $(41,0 \%)$ & $(45,9 \%)$ & $(40,5 \%)$ & \\
\multirow{2}{*}{ Sódio } & \multirow{2}{*}{$2.300,00 \mathrm{mg}$} & $3.860,65$ & $1.134,90$ & $2.023,49$ & $2.490,85$ & 844,77 & $1.564,25$ & $86,3 \%$ \\
& & $(167,8 \%)$ & $(49,3 \%)$ & $(87,9 \%)$ & $(108,2 \%)$ & $(36,7 \%)$ & $(68,0 \%)$ & \\
\multirow{2}{*}{ Zinco } & \multirow{2}{*}{$11,00 \mathrm{mg}$} & 26,65 & 4,18 & 13,42 & 15,64 & 5,87 & 9,84 & $114,5 \%$ \\
& & $(242,2 \%)$ & $(38,0 \%)$ & $(122,0 \%)$ & $(142,1 \%)$ & $(53,3 \%)$ & $(89,4 \%)$ & \\
\hline
\end{tabular}

*Recomendações de Micronutrientes baseadas na Ingestão Diária Recomendada de acordo com o sexo e a idade (IOM, 2010). Fonte: Autores.

$\mathrm{Na}$ Tabela 2, que representa o percentual de vitaminas ingeridas por meio dos alimentos, é possível verificar que somente a vitamina B12 (159,6\%) atingiu níveis acima da média adequada para consumo, de acordo com a IDR, embora haja relatos na literatura de se apresentarem baixos os níveis dessa vitamina em indivíduos com hemoglobinopatias, principalmente na presença de alterações gastrointestinais que dificultam sua absorção. Trata-se de uma vitamina de grande importância, pois atua colaborando na formação dos glóbulos vermelhos e na síntese do ácido nucléico e eritrócitos, atuando na regeneração do ácido fólico. É um micronutriente importante para o portador da DF, pois atua na transformação da homocisteína em metionina, e, consequentemente, reduz os riscos de desenvolvimento de doenças cardiovasculares (Vannucchi \& Cunha, 2009). As médias de consumo das vitaminas A $(17,6 \%)$, B9 $(11,4 \%)$, C $(47,2 \%)$, e D $(10,8 \%)$ não atingiram as necessidades de ingestão diária recomendada, no caso. 
A Vitamina B9 (ácido fólico) tem sido suprida pela diária suplementação que o adolescente ingere devido à importância da mesma para manutenção da DF devido à destruição celular aumentada, agindo na produção de novas células sanguíneas, na maturação das hemácias, e na síntese do S-adenosilmetionina (SAM) que atua no processo de divisão celular. Além da necessidade de fazer o uso do suplemento vitamínico diário, é importante que o adolescente tenha uma alimentação mais rica em ácido fólico (Cehmob, 2018).

Nesse estudo, a condição mais detectada foi à insuficiência/deficiência de vitamina $\mathrm{A}$ e $\mathrm{D}$, respectivamente, sendo que em três, dos seis dias, não houve aporte nenhum desse grupo. A deficiência de vitaminas é uma das condições nutricionais mais comuns entre pessoas com DF, e existem características específicas que podem contribuir para esse fenômeno. Uma delas é a falta de apetite que pode ocorrer na presença da doença e em pacientes hospitalizados, além da produção constante de glóbulos vermelhos para compensar a sobrevivência reduzida de glóbulos vermelhos (Aljama et al., 2018).

Cerca de 13\% da população geral apresentam riscos de hipovitaminose D, segundo dados da pesquisa do National Health and Nutrition Examination Survey (NHANES) (Manson et al., 2016). A vitamina D na forma dietética só converte cerca de $1 \%$, sendo de extrema importância o banho de sol diário, para que a absorção dessa vitamina seja efetiva. Evidenciase, na literatura, uma alta prevalência de complicações endócrinas e alterações metabólicas na população com DF, sendo a vitamina $\mathrm{D}$ a condição mais detectada relacionada à hipovitaminose. Há, também, uma relação negativa significativa entre níveis plasmáticos de vitamina D e gravidade clínica da doença, representada pelo número de internações (Dougherty et al., 2015; Aljama et al., 2018; Mandese et al., 2019).

A vitamina D é conhecida devida importância da sua função relacionada ao metabolismo ósseo na adolescência, pois atua na absorção do cálcio o que influencia no pico de massa óssea ideal nessa faixa etária. Além dessa função, é responsável também por outras como reguladora do sistema imunológico, cardiovascular, metabolismo e insulina. Tais fatores podem agravar ou determinar a falha no desenvolvimento de crianças e adolescentes com DF (Cehmob, 2018). Além da vitamina D ser vital para a saúde óssea e para a manutenção do cálcio, é responsável também por manter o nível de fosfato sérico normal, bem como efeito importante na função imune, proliferação celular, diferenciação e apoptose (Aljama et al., 2018).

As úlceras de membro inferiores, ou úlceras de perna como comumente são conhecidas, estão presentes em 8 a $10 \%$ das pessoas com DF. São feridas que se iniciam na adolescência, e surgem frequentemente após picadas de insetos e traumas malcuidados. São muito dolorosas e normalmente ficam crônicas (Brasil, 2018; Cehmob, 2018). Para a manutenção da epiderme normal e cicatrização de feridas como as úlceras de perna, a vitamina A é essencial, pois baixos níveis podem diminuir a estabilidade de colágeno e aumenta sua susceptibilidade à infecção (Cehmob, 2018).

A interferência negativa do aporte inadequado de vitamina $\mathrm{C}$ está relacionada com manifestações clínicas como a fadiga, perda de apetite, sonolência, palidez, falta de energia nos membros e articulações, irritabilidade, defeitos dentários. A vitamina $\mathrm{C}$ tem um papel importante para a síntese de colágeno e, com isso, ela é crítica para a cicatrização de feridas, onde pequenos ferimentos na pele, uma vez ocasionada em pessoas com DF, podem ser agravar (Cehmob, 2018). 
Tabela 3 - Percentual do consumo dos Micronutrientes: Minerais, de acordo com a alimentação fornecida ao adolescente pelo período de 6 dias, segundo dados do Recordatório Alimentar 24h.

\begin{tabular}{|c|c|c|c|c|c|c|c|c|}
\hline \multirow[t]{2}{*}{ Nutrientes } & \multirow{2}{*}{$\begin{array}{l}\text { Necessidades e } \\
\text { Recomendações } \\
\text { Nutricionais* }\end{array}$} & \multicolumn{7}{|c|}{ Valores Recordatório Alimentar 24h } \\
\hline & & $\begin{array}{c}\text { Segunda- } \\
\text { feira }\end{array}$ & $\begin{array}{c}\text { Terça- } \\
\text { feira }\end{array}$ & $\begin{array}{c}\text { Quarta- } \\
\text { feira }\end{array}$ & $\begin{array}{l}\text { Quinta- } \\
\text { feira }\end{array}$ & $\begin{array}{c}\text { Sexta- } \\
\text { feira }\end{array}$ & Sábado & $\begin{array}{c}\text { Média } \\
\text { percentual }\end{array}$ \\
\hline Cálcio & $1.300,00 \mathrm{mg}$ & $\begin{array}{c}761,04 \\
(58,5 \%)\end{array}$ & $\begin{array}{c}387,96 \\
(29,8 \%)\end{array}$ & $\begin{array}{c}171,39 \\
(13,1 \%)\end{array}$ & $\begin{array}{c}394,39 \\
(30,3 \%)\end{array}$ & $\begin{array}{c}361,75 \\
(27,8 \%)\end{array}$ & $\begin{array}{c}175,80 \\
(13,5 \%)\end{array}$ & $36,01 \%$ \\
\hline Ferro & $11,00 \mathrm{mg}$ & $\begin{array}{c}25,31 \\
(230,0 \%)\end{array}$ & $\begin{array}{c}10,40 \\
(91,5 \%)\end{array}$ & $\begin{array}{c}13,82 \\
(125,6 \%)\end{array}$ & $\begin{array}{c}15,91 \\
(144,6 \%)\end{array}$ & $\begin{array}{c}12,30 \\
(111,8 \%)\end{array}$ & $\begin{array}{c}12,91 \\
(117,3 \%)\end{array}$ & $136,8 \%$ \\
\hline Magnésio & $410,00 \mathrm{mg}$ & $\begin{array}{l}399,01 \\
(97,3 \%)\end{array}$ & $\begin{array}{l}228,70 \\
(55,7 \%)\end{array}$ & $\begin{array}{l}267,65 \\
(65,2 \%)\end{array}$ & $\begin{array}{c}228,89 \\
(55,8 \%)\end{array}$ & $\begin{array}{c}300,66 \\
(73,3 \%)\end{array}$ & $\begin{array}{l}252,41 \\
(61,5 \%)\end{array}$ & $68,13 \%$ \\
\hline Potássio & $4.700,00 \mathrm{mg}$ & $\begin{array}{l}3.584,71 \\
(76,2 \%)\end{array}$ & $\begin{array}{l}1.840,73 \\
(39,1 \%)\end{array}$ & $\begin{array}{c}2.330,06 \\
(49,5 \%)\end{array}$ & $\begin{array}{l}1.927,22 \\
(41,0 \%)\end{array}$ & $\begin{array}{l}2.160,09 \\
(45,9 \%)\end{array}$ & $\begin{array}{l}1.905,70 \\
(40,5 \%)\end{array}$ & $48,7 \%$ \\
\hline Sódio & $2.300,00 \mathrm{mg}$ & $\begin{array}{l}3.860,65 \\
(167,8 \%)\end{array}$ & $\begin{array}{l}1.134,90 \\
(49,3 \%)\end{array}$ & $\begin{array}{l}2.023,49 \\
(87,9 \%)\end{array}$ & $\begin{array}{l}2.490,85 \\
(108,2 \%)\end{array}$ & $\begin{array}{c}844,77 \\
(36,7 \%)\end{array}$ & $\begin{array}{l}1.564,25 \\
(68,0 \%)\end{array}$ & $86,3 \%$ \\
\hline Zinco & $11,00 \mathrm{mg}$ & $\begin{array}{c}26,65 \\
(242,2 \%)\end{array}$ & $\begin{array}{c}4,18 \\
(38,0 \%)\end{array}$ & $\begin{array}{c}13,42 \\
(122,0 \%)\end{array}$ & $\begin{array}{c}15,64 \\
(142,1 \%)\end{array}$ & $\begin{array}{c}5,87 \\
(53,3 \%)\end{array}$ & $\begin{array}{c}9,84 \\
(89,4 \%)\end{array}$ & $114,5 \%$ \\
\hline
\end{tabular}

*Recomendações de Micronutrientes baseadas na Ingestão Diária Recomendada de acordo com o sexo e a idade (IOM, 2010). Fonte: Autores.

Na Tabela 3, nota-se que, de todos os minerais, o cálcio foi o que obteve menor aporte, com média percentual de 36,01\%. Mas, comparando-se com as vitaminas, os minerais tiveram uma melhor distribuição percentual, sendo consumidos em valor igual ou superior a 50\% da IDR, mesmo considerando os dias em que houve episódios de enjoo, baixa ingesta alimentar e menor valor em consumo energético. Assim como no estudo de Mandese et al. (2016) após análises bioquímicas os minerais também se encontraram em níveis abaixo do recomendado. Os minerais têm elevada relevância na saúde das pessoas com DF e no desenvolvimento sadio na adolescência.

O cálcio e a vitamina D estão envolvidos no metabolismo ósseo. Os fatores genéticos são responsáveis por variações de 40 a $80 \%$ nas diferenças dos ganhos do pico de massa óssea. Uma baixa ingestão de cálcio pode ocasionar a redução do pico de massa óssea ideal na criança e adolescente (Soe et al., 2017; Cehmob, 2018). Dentro de níveis de IMC adequados e saudáveis na adolescência, existe a correlação positiva entre níveis de cálcio e a Densidade Mineral Óssea (DMO), sendo que uma ingestão inadequada pode prejudicar a retenção de cálcio pelo esqueleto, favorecendo déficits no desenvolvimento de adolescentes (Sbp, 2017). Tais fatores podem agravar ou determinar a falha de crescimento do adolescente com DF.

Nesse estudo, o adolescente apresentou média de (136,8\%) no consumo alimentar de ferro, estando em nível acima da IDR, contrariando o que está posto na literatura. O estudo de Mandese e colaboradores (2016) mostra a presença da deficiência de ferro em pessoas com DF. Na adolescência a deficiência de ferro está associada a uma redução do crescimento físico e intelectual, o que pode trazer prejuízos para o adolescente. Mas a deficiência de ferro poderia atuar de forma benéfica na redução da falcização dos glóbulos vermelhos, diminuindo a concentração média de hemoglobina corpuscular com redução sequente de hemólise e crises dolorosas.

A dosagem de ferro sérico nas pessoas com DF é frequentemente realizada para evitar o possível acúmulo desse mineral na corrente sanguínea, principalmente quando os indivíduos são tratados com hemotranfusão, sendo necessário o uso de quelante de ferro, caso se encontre em níveis acima do esperado. Seria necessária uma avaliação clínica frequente a fim de 
Research, Society and Development, v. 10, n. 7, e10010715982, 2021

(CC BY 4.0) | ISSN 2525-3409 | DOI: http://dx.doi.org/10.33448/rsd-v10i7.15982

controlar os níveis desse mineral para que não seja deficiente e ocasione o atraso no desenvolvimento do adolescente, mas, também, para que não se acumule e traga danos caso se apresente em altos níveis (Moreira \& Silva, 2014). O uso potencial da medicação hidroxiuréia pode melhorar o resultado clínico da doença influenciando positivamente no crescimento e o desenvolvimento, reduzindo o risco de sobrecarga de ferro devido às transfusões sanguíneas no paciente crônico (Mandese $e t$ al., 2019).

Uma alta prevalência de hipomagnesemia e hipocalcemia sérica foi observada entre os indivíduos com DF. O magnésio participa do controle da desidratação eritrocitária e crises vaso-oclusivos. Baixos níveis séricos de magnésio podem contribuir na redução da densidade mineral óssea em adolescentes com DF, além de ter papel significativo na pressão arterial, sistema imunológico e rítmico cardíaco. Na célula falciforme, a anormalidade na permeabilidade dos glóbulos vermelhos e a perda de potássio favorecem a propensão para desidratação dos glóbulos vermelhos. Assim, níveis mais elevados de magnésio intracelular podem bloquear esta via e reduzir a desidratação, bem como a falcização em pessoas com DF. Outros estudos sugerem que o consumo de potássio na dieta tem efeitos benéficos na pressão arterial sistólica e diastólica, e que consumir mais alimentos ricos nesse mineral durante a infância pode ajudar a suprimir o aumento da pressão arterial na adolescência. A hipertensão arterial pulmonar é uma complicação comum em na DF e é um fator de risco muito importante nestes pacientes (Naoum \& Naoum, 2004; Antwi-boasiako et al., 2019; Bakris et al., 2015).

O sódio participa de diversas funções básicas no organismo, como, contração muscular, impulsos nervosos, ritmo cardíaco, equilíbrio ácido-base, equilíbrio de água no organismo, impede o endurecimento do cálcio e do magnésio, o que pode formar cálculos biliares ou nefríticos; previne a coagulação sanguínea sendo então fundamental para a saúde. O adolescente apresentou média percentual na ingesta desse mineral de $86,3 \%$, se aproximando da IDR. Não foram encontrados estudos com avaliação percentual do sódio na $\mathrm{DF}$, mas foi relacionado ao tratamento preventivo da úlcera de perna, onde é indicado restringir seu uso. As úlceras comprometem, de forma considerável, a qualidade de vida dos indivíduos, e estão presentes em 8\% a 10\% das pessoas com DF. Estudos revelam o elevado conteúdo de sódio na alimentação dos adolescentes e está associado ao alto consumo de alimentos industrializados (Veiga et al., 2013). O consumo de sódio, portanto, é importante para um bom desenvolvimento do organismo, porém, é preciso que se consuma na medida certa para não trazer agravos a saúde.

A deficiência de zinco é relatada há tempos na literatura (Prasad et al., 1975), contudo o adolescente apresentou uma média de $114,5 \%$, ultrapassando a IDR. Estudos recentes corroboram esses antigos relatos, devido a importância desse mineral no prognóstico da DF. Níveis séricos mais baixos de zinco na DF são parcialmente devidos a fatores que incluem a redução da reabsorção de zinco nos túbulos renais devido à falcização e metabolismo alterado (Antwi-boasiako et al., 2019; Datta et al., 2019). O zinco desempenha papel importante no crescimento e na maturação sexual podendo ser um fator limitante do crescimento na adolescência. A alteração da homeostase do zinco pode influenciar o sistema de defesa antioxidante e, consequentemente, levar ao estresse oxidativo, favorecendo o aumento de infecções oportunistas e, consequentemente, da taxa de mortalidade. Uma alta proporção indivíduos com DF apresentaram deficiência em zinco, e a suplementação de zinco demonstrou diminuir o risco de infecção em adolescentes e adultos (Datta et al., 2019). Além da suplementação, é importante que na alimentação dessa população sejam orientados alimentos ricos em zinco, por ser um cofator para várias enzimas, que desempenham um papel importante na reparação de feridas (Cehmob, 2018).

$\mathrm{Na}$ entrevista, usada como recurso para auxiliar a desenvolver um entendimento das circunstâncias que influenciam o adolescente nas suas escolhas alimentares, e se possui relação com a sua percepção de saúde diante da patologia acometida, mostra que o adolescente classifica seus hábitos alimentares atualmente como "[...] Mediano". Ao questionar se o adolescente tem dúvidas ou preocupação com relação à sua alimentação, ele refere que tem “[...] Um pouco em questão de beber água." Se há algo que sua família poderia fazer para te auxiliar com relação a sua alimentação, o adolescente diz que "[...] Sim, me lembrar de comer verduras e beber água." 
Por fim, mesmo que de forma objetiva, é possível observar que o adolescente compreende a necessidade na melhora de seus hábitos alimentares e que possui dificuldades em relação ao consumo de verduras. Problema esse, recorrente apresentado no período da adolescência devido à autonomia nas escolhas alimentares, que por muitas vezes são por alimentos de baixo valor nutritivo. A desidratação pode causar crises de dor devido ao aumento da viscosidade sanguínea, o que leva a vaso-oclusão e hemólise. Para a melhora na condição de saúde da DF, é muito importante à ingestão de líquidos ao longo do dia, principalmente água (Cehmob, 2018).

\section{Considerações Finais}

Por se tratar de uma doença de importância genética, bioquímica, hematológica, clínica, antropológica e epidemiológica, cujo prognóstico está fortemente associado ao contexto socioeconômico e à assistência de saúde oferecida, é importante conhecer sua evolução e a qualidade da assistência, objetivando a elaboração de intervenções que visem controlar a doença e reduzir a morbidade por DF, principalmente no público adolescente, cujas fontes de informação específicas são escassas na literatura.

A nutrição adequada do adolescente é uma das necessidades básicas de saúde para que possam expressar adequadamente o seu potencial genético. A DF pode desempenhar um papel importante na falha do crescimento e desenvolvimento de adolescentes em comparação com seus pares saudáveis.

A avaliação nutricional é um conjunto de métodos usados para diagnosticar o estado nutricional de indivíduos e/ou populações. Índices antropométricos, avaliação da ingesta alimentar e exames bioquímicos são combinações para avaliação do estado nutricional de adolescentes. Esse acompanhamento deve fazer parte da rotina nos indivíduos com DF, pois as mudanças no estado nutricional em adolescentes podem ser muito rápidas devido à progressão da doença e as necessidades dessa fase da vida, elevando o risco de os pacientes regredirem seu quadro clínico e dificultando o tratamento da doença.

A adolescência é uma etapa fundamental na aquisição de hábitos alimentares, na qual ocorre um incremento na autonomia de decisão. Quando iniciada de forma precoce, a intervenção nutricional na adolescência auxilia nos cuidados da pessoa com DF em relação ao prognóstico da doença, contribuindo para diminuição do tempo de internação, associando-se diretamente a sua recuperação. Na equipe, o profissional nutricionista se torna essencial na rotina de saúde, pois é o profissional capacitado especificamente para conduzir a conduta dietoterápica do paciente.

Quando a família se preocupa com o que é servido à mesa e compartilha o momento da refeição, fortalece os laços de afeto entre os seus integrantes e promove um cuidado que repercute na saúde de todos os seus membros. $\mathrm{O}$ envolvimento dos pais com a rotina alimentar é fundamental para que o adolescente desenvolva uma consciência e a autonomia mais ampla em relação ao que consome, entendendo como o que ingere influência na sua saúde e no prognóstico da DF.

Para maior aprofundamento no tema, recomenda-se a realização de avaliação bioquímica para dosagem dos níveis séricos das vitaminas e minerais, e a coleta de dados realizada de forma presencial, com maior número de adolescentes com DF, o que não foi possível no atual período de restrição de contato pela pandemia da COVID-19, o que se torna um limitante desse estudo.

Ademais, ainda faltam estudos que mostrem a importância da avaliação e monitoramento do estado nutricional nos adolescentes portadores da DF. Estima-se que os resultados desse estudo se tornem fontes de informação para a sociedade e de grande valia no contexto público de saúde, contribuindo para que outros profissionais de saúde possam perceber as necessidades dos indivíduos crônicos e buscar o melhor tratamento de forma integral e humanizada, e não apenas fixar-se nas manifestações clínicas relacionadas e conhecidas da doença. 
Acredita-se que este estudo possa trazer benefícios de curto, médio e longo prazo para os adolescentes com DF, para suas famílias, para a comunidade, para as instituições formadoras e para a ciência, uma vez que a identificação do estado nutricional dos adolescentes com a DF, favorece o planejamento de ações voltadas para a promoção da saúde, de modo a minimizar o prejuízo para a qualidade de vida em todo o ciclo de vida do adolescente.

\section{Referências}

AlJama, A., AlKhalifah, M., Al-Dabbous, I. A., \& Alqudaihi, G. (2018). Vitamin D deficiency in sickle cell disease patients in the Eastern Province of Saudi Arabia. Annals of Saudi medicine, 38(2), 130-136.

Antwi-Boasiako, C., Kusi-Mensah, Y. A., Hayfron-Benjamin, C., Aryee, R., Dankwah, G. B., Kwawukume, L. A., \& Darkwa, E. O. (2019). Total Serum Magnesium Levels and Calcium-To-Magnesium Ratio in Sickle Cell Disease. Medicina, 55(9), 547.

Agência Nacional de Vigilância Sanitária (Anvisa). Manual de Diagnóstico e Tratamento de Doença Falciforme.

Bakris, G. L., Pitt, B., Weir, M. R., Freeman, M. W., Mayo, M. R., Garza, D., \& Bushinsky, D. A. (2015). Effect of patiromer on serum potassium level in patients with hyperkalemia and diabetic kidney disease: the AMETHYST-DN randomized clinical trial. Jama, 314(2), 151-161.

Bardln, L. (2011). Análise de conteúdo. São Paulo: edições, 70, 229.

Brasil (2014). Ministério da Saúde. Secretaria de Atenção à Saúde. Departamento de Atenção Hospitalar e de Urgência. Doença falciforme: o que se deve saber sobre herança genética / Ministério da Saúde, Secretaria de Atenção à Saúde, Departamento de Atenção Hospitalar e de Urgência - Brasília: Ministério da Saúde.

Brasil (2018). Ministério da Saúde. Secretaria de Atenção à Saúde. Departamento de Ações Programáticas e Estratégicas. Proteger e cuidar da saúde de adolescentes na atenção básica/Ministério da Saúde, Secretaria de Atenção a Saúde, Departamento de Ações Programáticas e Estratégicas. - Brasília: Ministério da Saúde, 2.ed.

Centro de Educação e Apoio para Hemoglobinopatias (Cehmob) (2018). Manual Informativo: Doença Falciforme: Linha de cuidados na Atenção Primária para Nutricionistas / CEHMOB. NUPAD/FM/UFMG.

Cox, S. E., Makani, J., Fulford, A. J., Komba, A. N., Soka, D., Williams, T. N., \& Prentice, A. M. (2011). Nutritional status, hospitalization and mortality among patients with sickle cell anemia in Tanzania. haematologica, 96(7), 948.

Dahmani, F., Benkirane, S., Kouzih, J., Woumki, A., Mamad, H., \& Masrar, A. (2016). Etude de l'hémogramme dans la drépanocytose homozygote: à propos de 87 patients. The Pan African Medical Journal, 25.

Datta, D., Namazzi, R., Conroy, A. L., Cusick, S. E., Hume, H. A., Tagoola, A., \& John, C. C. (2019). Zinc for Infection Prevention in Sickle Cell Anemia (ZIPS): study protocol for a randomized placebo-controlled trial in Ugandan children with sickle cell anemia. Trials, 20(1), 1-11.

Dougherty, K. A., Bertolaso, C., Schall, J. I., Smith-Whitley, K., \& Stallings, V. A. (2015). Safety and efficacy of high dose daily vitamin d3 supplementation in children and young adults with sickle cell disease. Journal of pediatric hematology/oncology, 37(5), e308.

Dietbox (2021). Software de nutrição. https://dietbox.me/pt-BR.

Gil, A. C. (2002). Como elaborar projetos de pesquisa. 4, 175.

Institute of medicine (IOM) (2002). Dietary Reference Intakes for Energy, Carbohydrate, Fiber, Fat, Fatty Acids, Cholesterol, Protein, and Amino Acids (Macronutrients). The National Academy Press, Washington, D.C.

Institute of medicine (IOM) (2011). Food and Nutrition Board. Dietary reference intakes. National Academy Press.

Li-Thiao-Te, V., Uettwiller, F., Quartier, P., Lacaille, F., Bader-Meunier, B., Brousse, V., \& de Montalembert, M. (2018). Coexistent sickle-cell anemia and autoimmune disease in eight children: pitfalls and challenges. Pediatric Rheumatology, 16(1), 1-6.

Mandese, V., Marotti, F., Bedetti, L., Bigi, E., Palazzi, G., \& Iughetti, L. (2015). Effects of nutritional intake on disease severity in children with sickle cell disease. Nutrition journal, 15(1), 1-6.

Manson, J. E., Brannon, P. M., Rosen, C. J., \& Taylor, C. L. (2016). Vitamin D deficiency-is there really a pandemic. N Engl J Med, 375(19), 1817-1820.

Moreira, M. C. N., Albernaz, L. V., Sá, M. R. C. D., Correia, R. F., \& Tanabe, R. F. (2017). Recomendações para uma linha de cuidados para crianças e adolescentes com condições crônicas complexas de saúde. Cadernos de Saúde Pública, 33, e00189516.

Moreira, A. S., \& Silva, R. A. A. (2014). Anemia ferropriva em portadores de anemia falciforme: a importância de se avaliar o estado nutricional de ferro. Revista de Ciências Médicas e Biológicas, 13(2), 236-241.

Marques, L. N., Cavalcanti, A., \& Ruzzi-Pereira, A. (2015). O viver com a doença falciforme: percepção de adolescentes. Revista de Terapia Ocupacional da Universidade de São Paulo, 26(1), 109-117.

Prasad, A. S., Schoomaker, E. B., Ortega, J., Brewer, G. J., Oberleas, D., \& Oelshlegel Jr, F. J. (1975). Zinc deficiency in sickle cell disease. Clinical chemistry, 21(4), 582-587. 
Research, Society and Development, v. 10, n. 7, e10010715982, 2021

(CC BY 4.0) | ISSN 2525-3409 | DOI: http://dx.doi.org/10.33448/rsd-v10i7.15982

Santos, T. A., Santos, H. S., Mascarenhas, N. B., \& de Melo, C. M. M. (2018). O materialismo dialético e a análise de dados quantitativos. Texto \& Contexto.

Santos, I. N. D., Damião, J. D. J., Fonseca, M. D. J. M. D., Cople-Rodrigues, C. D. S., \& Aguiar, O. B. D. (2019). Insegurança alimentar e apoio social em famílias de crianças com doença falciforme. Jornal de Pediatria, 95(3), 306-313.

Sociedade Brasileira de Pediatria (SBP) (2021). Como otimizar a ingestão de cálcio e o ganho de massa óssea em adolescentes.Departamento Científico de Adolescência. Guia Prático de Atualização. n 5, junho.

Sociedade Brasileira de Pediatria (SBP) (2017). Higiene do Sono. Departamentos científicos de Adolescência e do Sono. Copyright @ 2021. Acesso em: 23 jan. 2021. Disponível em: https://www.sbp.com.br/especiais/pediatria-para-familias/desenvolvimento/higiene-do-sono/.

Soe, H. H. K., Abas, A. B., Than, N. N., Ni, H., Singh, J., Said, A. R. B. M., \& Osunkwo, I. (2020). Vitamin D supplementation for sickle cell disease. Cochrane Database of Systematic Reviews, (5).

Souza, K. C. M. D., Araújo, P. I. C. D., Souza-Junior, P. R. B., \& Lacerda, E. M. D. A. (2011). Baixa estatura e magreza em crianças e adolescentes com doença falciforme. Revista de Nutrição, 24(6), 853-862.

Vannucchi, H., \& Cunha, S. F. C. (2009). Funções Plenamente Reconhecidas de Nutrientes: Vitaminas do Complexo B: Tiamina, Riboflavina, Niacina, Piridoxina, Biotina e Ácido Pantotênico. Comitê de nutrição, ILSI Brasil: São Paulo.

Veiga, G. V. D., Costa, R. S. D., Araújo, M. C., Souza, A. D. M., Bezerra, I. N., Barbosa, F. D. S., ... \& Pereira, R. A. (2013). Inadequação do consumo de nutrientes entre adolescentes brasileiros. Revista de Saúde Pública, 47, 212s-221s.

Wasnik, R. R., \& Akarte, N. R. (2017). Evaluation of Serum Zinc and Antioxidant Vitamins in Adolescent Homozygous Sickle Cell Patients in Wardha, District of Central India. Journal of clinical and diagnostic research: JCDR, 11(8), BC01.

World Health Organizations (WHO) (2007). Growht reference data for 5-19 years. https://www.who.int/growthref/en/.

Zago, M. A., \& Pinto, A. C. S. (2007). Fisiopatologia das doenças falciformes: da mutação genética à insuficiência de múltiplos órgãos. Revista Brasileira de Hematologia e Hemoterapia, 29(3), 207-214. 